\title{
PROFIL KONDISI FISIK ATLTE KARATE JUNIOR PUTRA PERGURUAN INKANAS KOTA BENGKULU TAHUN 2019
}

\author{
Twoson Efriadi Gultom \\ email : twoson46@gmail.com \\ Universitas Bengkulu
}

Sugiyanto

Universitas Bengkulu

Defliyanto

Universitas Bengkulu

\begin{abstract}
Abstrak
Penelitian ini bertujuan untuk mengetahui profil fisik kondisi fisik atlet karate junior putra perguruan Inkanas kota Bengkulu tahun 2019. Penelitian ini merupakan penelitian deskriptif kuantitatif. Dalam penelitian ini, Sampel yang digunakan adalah atlet karate junior putra perguruan Inkanas kota Bengkulu sebanyak 30 atlet putra. Instrumen yang digunakan antara lain: 1) power otot tungkai dengan vertical jump, 2) kecepatan dengan sprint 50 meter, 3) kelentukan dengan sit and reach, 4) daya tahan dengan MFT ( multi stage fitnes test ) Analisis data dalam penelitian ini dikelompokkan menjadi lima kategori yaitu: baik sekali, baik, sedang, kurang, dan kurang sekali. Berdasarkan hasil penelitian dan pembahasan, penelitian ini menyimpulkan bahwa kondisi fisik atlet karate junior putra perguruan Inkanas Kota Bengkulu tahun 2019, yaitu sebanyak 0 atlet (0\%) dalam kategori baik sekali, 9 atlet (30\%) dalam kategori baik, 20 atlet (67\%) dalam kategori sedang, 1 atlet (3\%) dalam kategori kurang, dan 0 atlet (0\%) dalam kategori sangat kurang.
\end{abstract}

Kata Kunci : profil kondisi fisik, atlet karate junior, perguruan inkanas

\begin{abstract}
This study aims to determine the physical profile of the physical condition of male junior karate athletes in Inkanas University in Bengkulu in 2019. This research is a quantitative descriptive study. In this study, the sample used was 30 male athletes from the Inkanas college in Bengkulu city. The instruments used include: 1) leg muscle power with vertical jump, 2) speed with 50 meter sprint, 3) flexibility with sit and reach, 4) resistance with MFT (multi stage fitness test) Analysis of data in this study are grouped into five categories namely: very good, good, moderate, lacking, and very poor. Based on the results of research and discussion, this study concluded that the physical condition of male junior karate athletes in Bengkulu City Inkanas in 2019, namely 0 athletes (0\%) in the excellent category, 9 athletes (30\%) in the good category, 20 athletes (67\%) in the moderate category, 1 athlete $(3 \%)$ in the less category, and 0 athletes $(0 \%)$ in the very less category.
\end{abstract}

Keywords: profile of physical condition, junior karate athlete, college inkanas. 


\section{PENDAHULUAN}

Pada era globalisasi saat ini masyarakat Indonesia sudah mulai menyadari bawah pemeliharaan kesehatan sangat mutlak di perlukan selama manusia masih mengkehendaki hidup sehat jasmani dan rohani. Hal ini terbukti masyarakat Indonesia berlomba-lomba melakukan kegiatan jasmani dan rohani, bahkan telah sering menyelenggarakan kompetisi yang bersifat daerah, nasional, bahkan internasional.

Olahraga sangat penting bagi manusia bukan hanya untuk kesehatan tapi juga menggalang kebersamaan antar kelompok serta semangat persatuan. Karena olahraga terkait dalam berbagai bidang, seperti ekonomi, sosial dan politik bahkan dapat diandalkan untuk nama baik negara. dari sistem keolahragaan nasional sesuai dengan UU RI nomor 3 tahun 2005 pasal 21 ayat 3 dan 4, (1)pembinaan dan pengembangan keolahragaan di laksanakan melalui tahap pengenalan olahraga, pemantauan, pemanduan, serta pengembangan bakat dan peningkatan prestasi. (2) Pembinaan dan pengembangan keolahraga dilaksanakan melalui jalur keluarga, jalur pendidikan, dan jalur masyarakat yang berbasis pada pengembaan olahraga untuk semua orang yang berlangsung sepanjang hayat.

Dalam dunia olahraga setiap orang yang menekuni dan menggeluti suatu cabang olahraga biasanya diasumsikan memiliki tubuh dengan kondisi fisik yang baik, karena tanpa hal itu seseorang/atlet akan mengalami kesulitan dalam melakukan aktivitas olahraga yang ditekuninya dan digeluti. Bagi seorang atlet yang menjadikan olahraga sebagai sarana untuk meningkatkan prestasi maka memiliki kebugaran jasmani yang baik adalah mutlak harus dimiliki, tidak terkecuali dalam olahraga beladiri khususnya karate. Para atlet harus melakukan latihan-latihan yang telah diprogramkan oleh pelatih agar dapat mencapai target yang telah ditentukan sesuai dengan program latihan itu sendiri. Karena tanpa latihan yang teratur, terukur, dan kontinyu seorang atlet tidak akan bisa berprestasi secara maksimal. Atlet dengan kondisi fisik yang baik akan lebih mudah untuk menerima dan melakukan latihan, baik latihan fisik, teknik, taktik dan mental yang diberikan oleh pelatih (Maharani, 2016: 1).

Olahraga beladiri karate merupakan jenis olahraga beladiri body contact, cabang olahraga karate lebih terkait dengan intensitas tinggi saat bertanding. $\mathrm{Di}$ dalam pertandingan karate menurut peraturan WKF (Word Karate Federation) tahun 2018 kelompok usia 16-17 tahun di kategorikan junior, dengan di bagi menjadi 2 kelas yang di pertandingkan, kelas kumite adalah pertandingan untuk satu pertarungan yaitu 2 (dua) menit untuk putra junior (perorangan) dan $1 \frac{1}{2}$ (satu setengah) menit untuk putri junior dalam peraturan WKF (word karate faenerasion) tahun 2018. Kumite dibatasi oleh waktu, hal itu menjadikan situasi semakin menekan bagi para karateka yang bertanding, karena dalam waktu yang relatif pendek harus dapat mengalahkan lawan menggunakan teknik pertarungan yang sesuai dengan peraturan sehingga atlet memerlukan komponen fisik yang prima. Selanjutnya kelas kata yaitu jurus mempertandingkan kemampuan seseorang untuk mendemontrasikan dalam penguasaan ilmu beladiri karate tradisional dengan harmonisasi gerak yang mencerminkan kekuatan, kecepatan, kelincahan dan keindahan. Atlet yang bertanding pada pertandingan kata dan kumite harus memiliki kondisi fisik serta stamina yang baik dan bagus saat bertanding, selain itu juga harus memiliki keberagaman teknik yang baik serta mental bertanding yang mantap di saat 
bertanding menghadapi lawan yang ada di dalam matras (Maharani, 2016: 2).

Untuk mencapai kondisi fisik yang bagus, diperlukan latihan dan motivasi atlet yang tinggi dan disiplin saat latihan dengan mengaplikasikan metode-metode latihan. Seorang atlet karate, selain membutuhkan kekuatan, kelincahan, kecepatan reaksi, power dan ketahanan otot. Komponen fisik dasar yang baik diperlukan agar gerakan-gerakan dan bentuk teknik maupun taktik dapat bertahan lama dan optimal selama pertandingan di mulai dan berakhir (Maharani, 2016: 3).

Pada pertandingan karate, atlet saling bertarung untuk mendapatkan nilai atau poin agar meraih kemenangan. Untuk mencapai kemenangan diperlukan kondisi fisik atlet yang prima. Atlet karate seharusnya mempunyai daya tahan yang bagus, karena daya tahan merupakan salah satu komponen dasar yang penting dalam pertandingan karate. Dalam suatu pertandingan karate kemampuan teknik dan taktik seorang atlet harus didukung oleh komponen fisik yang baik. Pada pertandingan kumite, atlet saling bertarung untuk mendapatkan point atau nilai agar meraih kemenangan. Selama pertandingan akan terjadi bentuk (1) serangan baik menggunakan kaki maupun tangan, (2) melakukan serangan balik, (3) melakukan gerakan moving sebelum dan saat melakukan serangan, (4) pemberhentian waktu karena pemberian poin, peringatan, dan pemberian hukuman. Melihat kondisi dan waktu pertandingan yang demikian singkat dan intensitas tinggi, perlu latihan yang sesuai dengan komponen fisik dasar yang dibutuhkan, sehingga atlet tetap prima selama dalam melakukan pertandingan karate (Maharani, 2016: 4). Berdasarkan latar belakang masalah di atas, rumusan masalah dalam penelitian ini adalah: untuk mengetahui profil kondisi fisik atlet karate junior putra perguruan Inkanas pengcab kota Bengkulu tahun 2019.

\section{METODE}

Penelitian adalah suatu upaya
sistematis dalam menemukan,
menganalisis dan menafsirkan bukti-bukti empiris untuk memahami gejala atau menemukan jawaban terhadap suatu permasalahan yang terkait dengan gejala itu. Jenis penelitian ini merupakan penelitian diskriptif kuantitatif. Metode yang digunakan yaitu dengan menggunakan tes kondisi fisik yang bertujuan untuk mengungkapkan suatau apa adanya. Menurut Sugiyono (2016: 2) metode penelitian pada dasarnya merupakan cara ilmiah untuk mendapatkan data dengan tujuan dan kegunaan tertentu. Metode yang digunakan dalam penelitian ini adalah metode survey.

Metode survey digunakan untuk mendapatkan data dari tempat tertentu yang alamiah (bukan buatan) dalam pengumpulan data tes dan pengukuran.

menurut Suharsimi dalam Pujianto dan Insanistyo (2017: 71) populasi adalah keseluruhan subyek penelitian. Penelitian ini merupakan penelitian populasi karena data yang digunakan adalah seluruh atlet karate junior putra perguruan Inkanas pengcab kota Bengkulu sebanyak 30 atlet. teknik pengambilan sampel dalam penelitian ini dengan cara sampel total. Yaitu seluruh atlet karate junior putra perguruan Inkanas pengcab kota Bengkulu sebanyak 30 atlet.

Teknik pengumpulan data yang dilakukan dalam penelitian ini adalah tes dan pengukuran. Penelitian diawali dengan melengkapi biodata testi yang di berikan peneliti selanjutnya memberikan pemanasan kepada testi untuk mengurangi resiko cedera saat melakukan tes. Sebelumnya peneliti memberikan petunjuk 
yang harus dilakukan oleh testi agar tidak terjadi kesalahan saat melakukan tes, kemudian memberi kesempatan mencoba kepada testi untuk melakukan sebelum tes.

Tabel. 1.0 Instrumen peneliti kondisi fisik

\begin{tabular}{l|c|c|c} 
NO & Kondisi fisik & Tes & Satuan \\
\hline a. & $\begin{array}{c}\text { Power Otot } \\
\text { Tungkai }\end{array}$ & $\begin{array}{c}\text { Vertical } \\
\text { Jump Test }\end{array}$ & $\mathrm{Cm}$ \\
\hline b. & Kecepatan & $\begin{array}{l}\text { Sprint 50 } \\
\text { Meter }\end{array}$ & Detik \\
\hline c. & Fleksibilitas & $\begin{array}{c}\text { Sit and } \\
\text { Reach Test }\end{array}$ & $\mathrm{Cm}$ \\
\hline d. & Daya Tahan & $\begin{array}{c}\text { MFT (multi } \\
\text { stage } \\
\text { fitnes test) }\end{array}$ & $\begin{array}{c}\text { V02 } \\
\text { max }\end{array}$
\end{tabular}

HASIL DAN PEMBAHASAN

HASIL

Berdasarkan hasil penelitian, data yang diperoleh dari Kemampuan Fisik vertical jump atlet karate junior putra Inkanas pengcab kota Bengkulu tahun 2019 sebanyak 30 orang atlet putra diketahui bahwa nilai maksimum sebesar 26 , nilai minimum sebesar 19 , dengan ratarata 22,53, dan standar deviasi (SD) sebesar 2,14. Pada tes vertical jump seluruh atlet karate junior putra inkanas kota Bengkulu. Kategori penilaian sudah di tentukan ke dalam lima kategori status yaitu baik sekali, baik, cukup, kurang, dan kurang sekali. Kemudian untuk menghitung presentasi menggunakan rumus

$P=\frac{F}{N} \times 100 \%$.

kategorikan baik sekali $17 \% \quad(5$ orang), baik $40 \%$ (12 orang), cukup $43 \%$ (13 orang), kurang $0 \%$ dan kurang sekali $0 \%$. Setelah data Kemampuan Fisik vertical jump atlet karate junior putra Inkanas pengcab kota Bengkulu tahun 2019 didapat, dapat dilihat pada tabel dan gambar histogram sebagai berikut.
Tabel. 1.1 Data Kemampuan fisik vertical jump atlet karate Junior putra Inkanas Pengcab Kota Bengkulu Tahun 2019

\begin{tabular}{l|l|l|l|l} 
No & Norma & $\begin{array}{l}\text { Vertical } \\
\text { jump } \\
\text { Putra }\end{array}$ & Jumlah & $\%$ \\
\hline 1. & $\begin{array}{l}\text { Baik } \\
\text { Sekali }\end{array}$ & 25 & 5 & $17 \%$ \\
\hline 2. & Baik & 23 & 12 & $40 \%$ \\
\hline 3. & Cukup & 19 & 13 & $43 \%$ \\
\hline 4. & Kurang & 12 & 0 & $0 \%$ \\
\hline 5. & $\begin{array}{l}\text { kurang } \\
\text { sekali }\end{array}$ & 5 & 0 & $0 \%$ \\
\hline Jumlah & & 30 & $100 \%$
\end{tabular}

Gambar 1.0 Diagram Batang Data Kemampuan Fisik vertical jump atlet karate junior putra Inkanas pengcab kota Bengkulu tahun 2019

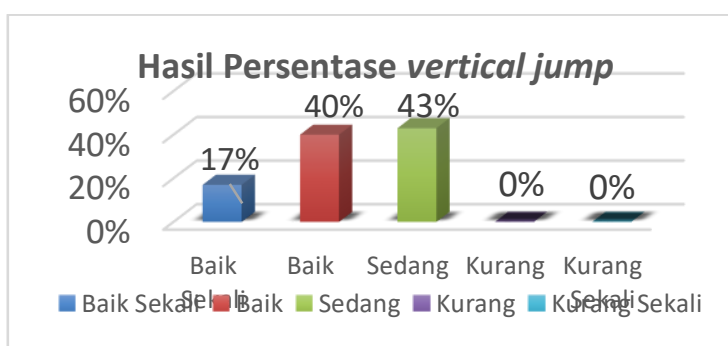

Kemampuan Fisik sprint 50 meter atlet karate junior putra Inkanas pengcab kota Bengkulu tahun 2019 sebanyak 30 orang atlet putra diketahui bahwa nilai maksimum sebesar 5,24, nilai minimum sebesar 4,75, dengan rata-rata 5,057, dan standar deviasi (SD) sebesar 0,139. Pada tes sprint 50 meter seluruh atlet karate junior putra inkanas kota Bengkulu melakukan sprint 50 meter sebanyak dua kali percobaan yang mana dari ke dua percobaan tersebut waktu yang terbaik yang diambil. kemudian untuk menghitung presentasi menggunakan rumus $P=\frac{F}{N} x 100 \%$.

kategorikan baik sekali $10 \%$ (3 orang), baik $50 \%$ (15 orang), sedang $40 \%$ (12 orang), kurang $0 \%$ dan kurang sekali 
$0 \%$. dapat dilihat pada tabel dan gambar histogram sebagai berikut.

Tabel. 1.2 Data Kemampuan fisik Sprint 50 meter atlet karate Junior putra Inkanas Pengcab Kota Bengkulu Tahun 2019

\begin{tabular}{l|l|l|l|l} 
No & Kategori & $\begin{array}{l}\text { Sprint 50 } \\
\text { Meter }\end{array}$ & Jumlah & $\%$ \\
\hline 1. & $\begin{array}{l}\text { Baik } \\
\text { Sekali }\end{array}$ & $<4.80$ & 3 & $10 \%$ \\
\hline 2. & Baik & $4.80-5.09$ & 15 & $50 \%$ \\
\hline 3. & Sedang & $5.10-5.29$ & 12 & $40 \%$ \\
\hline 4. & Kurang & $5.30-5.60$ & 0 & $0 \%$ \\
\hline 5. & $\begin{array}{l}\text { Kurang } \\
\text { Sekali }\end{array}$ & $>5.60$ & 0 & $0 \%$ \\
\hline \multicolumn{2}{l}{ Jumlah } & & 30 & $100 \%$
\end{tabular}

Gambar. 1.1 Distribusi Frekuensi Hasil Tes Sprint 50 meter

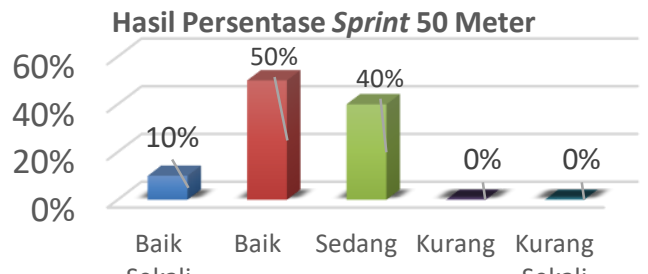

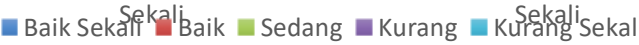

Kemampuan Fisik sit and reach atlet karate junior putra Inkanas pengcab kota Bengkulu tahun 2019 sebanyak 30 orang atlet putra diketahui bahwa nilai maksimum sebesar 18 , nilai minimum sebesar 10,5, dengan rata-rata 15,3, dan standar deviasi (SD) sebesar 2,362. Pada tes sit and reach seluruh atlet karate junior putra inkanas kota Bengkulu melakukan sit and reach sebanyak dua kali percobaan yang mana dari ke dua percobaan tersebut jangkauan terjauh yang diambil. kemudian untuk menghitung presentasi menggunakan rumus $P=\frac{F}{N} \times 100 \%$.

kategorikan baik sekali $53 \% \quad(16$ orang), baik $20 \%$ (6 orang), cukup $27 \%$ (8 orang), kurang $0 \%$ dan kurang sekali $0 \%$. Setelah data Kemampuan Fisik sit and reach atlet karate junior putra Inkanas pengcab kota Bengkulu tahun 2019 didapat, dapat dilihat pada tabel dan gambar histogram sebagai berikut.

Tabel. 1.3 Data Kemampuan fisik sit and reach atlet karate Junior putra Inkanas Pengcab Kota Bengkulu Tahun 2019

\begin{tabular}{l|l|l|l|l} 
No & Kategori & $\begin{array}{l}\text { Sit and } \\
\text { reach }\end{array}$ & $\begin{array}{l}\text { Jum } \\
\text { lah }\end{array}$ & $\%$ \\
\hline 1. & $\begin{array}{l}\text { Baik } \\
\text { Sekali }\end{array}$ & $>14$ & 16 & $53 \%$ \\
\hline 2. & Baik & $14.0-11.0$ & 6 & $20 \%$ \\
\hline 3. & Sedang & $10.9-7.0$ & 8 & $27 \%$ \\
\hline 4. & Kurang & $6.9-4.0$ & 0 & $0 \%$ \\
\hline 5. & $\begin{array}{l}\text { Kurang } \\
\text { Sekali }\end{array}$ & $<4$ & 0 & $0 \%$ \\
\hline
\end{tabular}

Gambar. 1.2 Persentase Sit and reach Junior putra

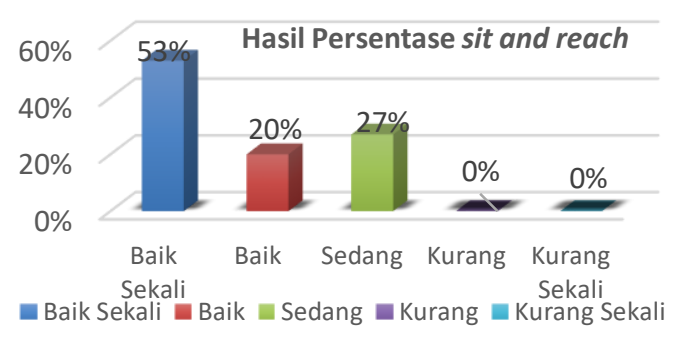

Kemampuan Fisik MFT (multi stage fitnes test) atlet karate junior putra Inkanas pengcab kota Bengkulu tahun 2019 sebanyak 30 orang atlet putra diketahui bahwa nilai maksimum sebesar 56,5 , nilai minimum sebesar 40,8 , dengan rata-rata 49,713, dan standar deviasi (SD) sebesar 3,954. Pada tes MFT (multi stage fitnes test) seluruh atlet karate junior putra inkanas kota Bengkulu melakukan MFT (multi stage fitnes test) sebanyak satu kali percobaan yang mana dari satu kali percobaan level dan shutle yang tertinggi akan dicatat.

kategorikan baik sekali $0 \%$, baik $50 \%$ (15 orang), sedang $40 \%$ (12 orang), kurang $10 \%$ (3 orang) dan kurang sekali $0 \%$. dapat dilihat pada tabel dan gambar histogram sebagai berikut. 
Tabel. 1.4 Data Kemampuan fisik MFT (multi stage fitnes test) atlet karate Junior putra Inkanas Pengcab Kota Bengkulu Tahun 2019

\begin{tabular}{l|l|l|l|l} 
No & Kategori & MFT & Jumlah & $\%$ \\
\hline 1. & $\begin{array}{l}\text { Baik } \\
\text { Sekali }\end{array}$ & $>57.1$ & 0 & $0 \%$ \\
\hline 2. & Baik & $\begin{array}{l}51.9- \\
57.0\end{array}$ & 15 & $\begin{array}{l}50 \\
\%\end{array}$ \\
\hline 3. & Sedang & $\begin{array}{l}43.9- \\
51.8\end{array}$ & 12 & $\begin{array}{l}40 \\
\%\end{array}$ \\
\hline 4. & Kurang & $\begin{array}{l}38.5- \\
43.8\end{array}$ & 3 & $\begin{array}{l}10 \\
\%\end{array}$ \\
\hline 5. & $\begin{array}{l}\text { Kurang } \\
\text { Sekali }\end{array}$ & $<38.4$ & 0 & $0 \%$ \\
\hline
\end{tabular}

Gambar. 1.3 Persentase MFT (multi stage fitnes test) junior putra

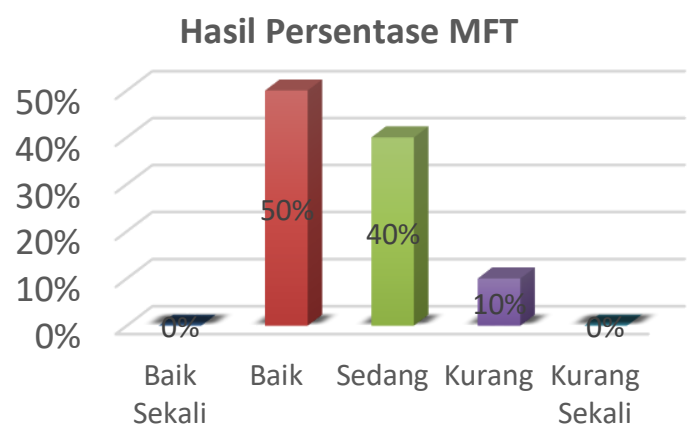

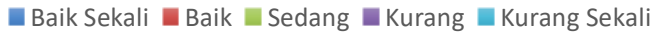

Berdasarkan data kemampuan fisik yang diukur dengan empat instrumen kemampuan fisik. Kemampuan fisik tersebut meliputi unsur power otot tungkai (vertical jump), kecepatan (sprint 50 meter), kelentukan (sit and reach), daya tahan MFT (multi stage fitnes test). yang didapatkan dari 30 atlet putra perguruan inkanas pengcab kota Bengkulu tahun 2019. Dari hasil ke 4 instrumen tes kemampuan fisik yang telah di konversi ke dalam lima kategori komponen status kondisi fisik yaitu baik sekali, baik, sedang, kurang, dan kurang. maka dapat diketahui nilai maksimum sebesar 9,5, nilai minimum sebesar 5,5, dengan nilai rata-rata, 7,366, dan Standar Deviasi (SD) sebesar 0,870. kemudian untuk menghitung presentasi menggunakan rumus $P=\frac{F}{N} \times 100 \%$.

Untuk kondisi Fisik yang telah di konversikan maka atlet karate junior putra Inkanas pengcab kota Bengkulu tahun 2019 sebanyak 30 orang atlet putra di kategorikan baik sekali $0 \%$, baik $30 \%$ (9 orang), sedang $67 \%$ (20 orang), kurang $3 \%$ (1 orang) dan kurang sekali $0 \%$. Setelah data kondisi Fisik karate junior putra Inkanas pengcab kota Bengkulu tahun 2019 didapat, dapat dilihat pada tabel dan gambar histogram sebagai berikut.

Tabel. 1.5 Status Kondisi Fisik atlet yang sudah dikonversik

\begin{tabular}{|c|c|c|c|c|}
\hline NO & $\begin{array}{l}\text { Rentang } \\
\text { Skor }\end{array}$ & $\begin{array}{l}\text { Kondisi fisik } \\
\text { dikonversikan }\end{array}$ & Jmlh & $\%$ \\
\hline 1. & 9.6-1.0 & baik sekali & 0 & $0 \%$ \\
\hline 2. & 8.0-9.5 & baik & 9 & $30 \%$ \\
\hline 3. & $6.0-7.9$ & Sedang & 20 & $67 \%$ \\
\hline 4. & 4.0-5.9 & Kurang & 1 & $3 \%$ \\
\hline 5. & 2.0-3.9 & kurang sekali & 0 & $0 \%$ \\
\hline \multicolumn{3}{|c|}{ Jumlah } & 30 & $100 \%$ \\
\hline
\end{tabular}

Gambar. 1.4 Hasil presentase profil kondisi fisik atlet karate junior putra perguruan inkanas pengcab kota Bengkulu tahun 2019

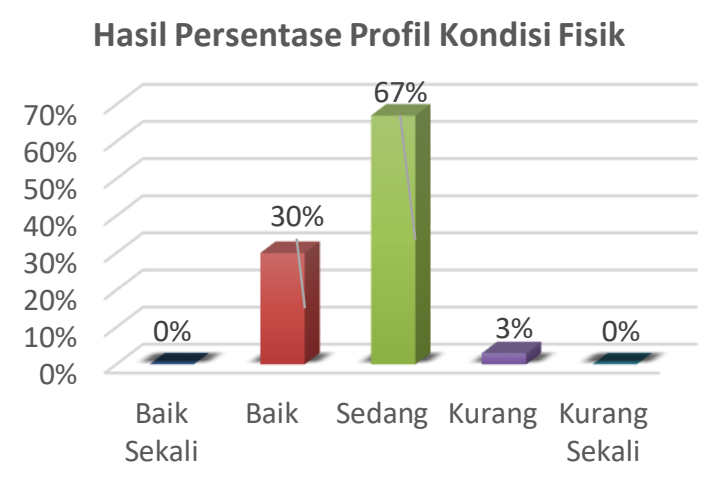

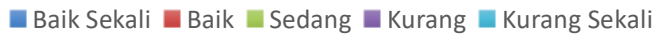




\section{PEMBAHASAN}

Berdasarkan hasil penelitian yang diperoleh bahwa pembahasan mengenai profil kondisi fisik atlet karate junior putra perguruan inkanas pengcab kota Bengkulu tahun 2019 yang terdiri dari 4 item tes 1 . Vertical jump, 2. Sprint 50 meter, 3. Sit and reach, 4. MFT (multi stage fitnes test) dengan menggunakan sampel seluruh atlet karate junior inkanas kota Bengkulu sebanyak 30 orang dengan mayortitas kondisi fisik atlet dari ke empat item tes berada di kategori sedang yaitu $67 \%$ (20 orang) dan kategorikan baik sekali $0 \%$, baik $30 \%$ (9 orang), kurang $3 \%$ (1 orang) dan kurang sekali $0 \%$, Untuk itu perlunya peningkatan kondisi fisik dengan cara latihan-terus-menurus dengan menggunakan prinsip-prinsip latihan. Latihan yang teratur dan berkesinambungan serta pengulangan gerakan yang semakin lama semakin meningkat, organisme-organisme dan mekanisme neurophysiologis kegiatan juga akan meningkat. Seperti dinyatakan oleh Per Odaf Astrand dan Kaare Rodahl dalam Moch Saleh (1982: 23) bahwa gerakangerakan akan menjadi otomatis, gerakan yang semula sukar dan mekanisme neurophysiologis yang bertambah baik. Untuk itu perlunya latihan secara terusmenerus dengan prinsip-prinsip latihan agar prestasi atlet meningkat. Menurut safrit dalam Arsil (2010: 5) pengukuran adalah proses pemberian angka-angka dari suatu objek, seseorang atau lainnya dengan mengikuti berbagai aturan. Dengan demikian pengukuran adalah untuk memperoleh besaran kuantitatif dari suatu obyek tertentu dengan menggunakan alat ukur (test) yang baku.

\section{PENUTUP}

\section{SIMPULAN DAN SARAN}

Berdasarkan hasil penelitian dan pembahasan yang diperoleh, penelitian ini dapat menyimpulkan bahwa status kondisi fisik atlet karate junior putra perguruan inkanas pengcab kota Bengkulu tahun 2019 sebanyak 30 atlet yang mana telah di konversikan ke lima kategori status kondisi fisik dari baik sekali, baik, sedang, kurang, kurang sekali. Dari ke empat instrumen tes kemampuan fisik atlet dengan tes power otot tungkai (vertical jump), kecepatan (sprint 50 meter), kelentukan (sit and reach), dan daya tahan (MFT). yaitu sebanyak 0 atlet $(0 \%)$ dalam kategori baik sekali, 9 atlet (30\%) dalam kategori baik, 20 atlet (67\%) dalam kategori sedang, 1 atlet (3\%) dalam kategori kurang, 0 atlet (0\%) dalam kategori kurang sekali. Sehubung dengan kesimpulan yang telah diambil, maka kepada pembina, pelatih disarankan untuk melakukan langkahlangkah sebagi berikut yang mana telah di lakukan peneliti dalam bentuk tes kondisi fisik:

1. Bagi atlet karate Inkanas kota bengkulu terutama pada atlet putra junior, agar memiliki motivasi diri yang tinggi dalam berlatih untuk meningkatkan kondisi fisik, karena fisik adalah faktor mendasar dari setiap cabang olahraga yang di geluti, terutama olahraga karate karena olahraga karate membutuhkan intensitas tinggi disaat pertandingan.

2. Bagi pelatih karate Inkanas kota Bengkulu agar dapat membuat program latihan untuk meningkatkan kondisi fisik atlet dari hasil penelitian yang telah dilakukan oleh peneliti, kondisi fisik atlet karate junior putra inkanas kota Bengkulu masih banyak berada di status kondisi fisik sedang. Maka dari itu perlunya ditingkatkan kondisi fisik.

3. Setelah membuat program kondisi fisik pelatih mengevaluasi kondisi fisik atlet minimal dua kali dalam satu tahunya, agar status kondisi fisik atlet dapat dilihat mengalami penurunan atau 
kenaikan status kondisi fisik atlet pertahunnya, semua hal itu dilakukan agar pengkontrolan kondisi fisik atlet dapat dilihat.

\section{DAFTAR PUSTAKA}

Arsil. 2010. Evaluasi Pendidikan Jasmani dan Olahraga. Padang : Fakultas Ilmu Keolahragaan Universitas Negeri Padang.

Lingga, Yarmani, dan Tono. 2017. "Pengaruh Latihan Beban GayaPegas Karet Ban Terhadap Kecepatan Pukulan Kumite Gyaku Tzuki Untuk Atlet Karate Inkanas Kota Bengkulu”. Jurnal Kinestetik, Vol. 1 (2).

Maharani, L.W. 2016. Profil Kemampuan Fisik Karate Porda Kabupaten Gunungkidul 2015 [Skripsi]. Yogyakarta : Universitas Negeri Yogyakarta.

Pujianto, D dan Insanistyo, B . 2017. Dasar Dasar Penelitian Pendidikan Jasmani. Bengkulu: FKIP Universitas Bengkulu.

Saleh, M. 1982. Bela Diri II. Jakarta. CV Gembira Jakarta. 